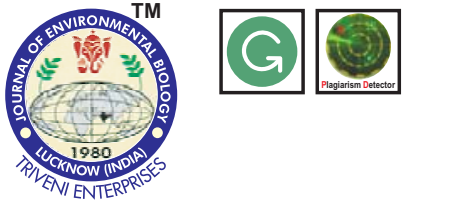

DOI : http://doi.org/10.22438/jeb/38/6/MRN-469

\title{
Evaluation of some novel insecticides, biopesticides and their combinations \\ against peach leaf curl aphid, Brachycaudus helichrysi infesting nectarine
}

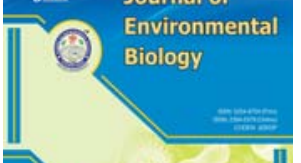

Authors Info

D. Gupta ${ }^{1 *}$, G. Singh', N. Thakur ${ }^{2}$ and R.S. Bhatia'

'Department of Entomology, Dr. Y.S. Parmar University of Horticulture and Forestry, Nauni (Solan) - 173230 , India

${ }^{2}$ Department of Fruit Science, Veer Chandra Singh Garhwali College of Horticulture, Uttarakhand University of Horticulture and Forestry, Bharsar, Pauri Garhwal - 246 123, India

*Corresponding Author Email : divender@rediffmail.com

Key words

Brachycaudus helichrysi

Biopesticides

Benefit cost ratio

Neonicotinoids

Nectarine

Publication Info

Paper received : 22.09 .2016

Revised received : 26.12 .2016

Re-revised received : 28.03.2017

Accepted : 10.05 .2017

\section{Abstract}

Aim : Nectarine (Prunus persica var. nucipersica) is an upcoming stone fruit crop in mid hills of Western Himalayas. Peach leaf curl aphid, Brachycaudus helichrysi (Kaltenbach) is a major regular pest which causes around $50 \%$ crop yield loss. Some biopesticides/plant products and neonicotinoids were evaluated against peach curl aphid, B. helichrysi in the present study.

Methodology : Two sprays of neonicotinoids namely, imidacloprid and thiamethoxam (both @0.008\% and $0.016 \%$ ), biopesticides viz. Econeem 10000 ppm ( 0.01 and $0.02 \%$ a.i), neem oil ( 1 and $2 \%$ ) were applied on nectarine trees twice (once at pink bud stage followed by at fruit set stage) in different combinations in a Randomised Block Design alongwith a recommended insecticide (oxy-demeton methyl @0.025\%). In one of the treatment only winter pruning was carried out and no pesticide was applied. The observations on infestation and aphid count was recorded after 7,14 and 21 days of second foliar application. The avoidable loss and benefit cost ratio were also calculated.

Results : Foliar applications of imidacloprid and thiamethoxam (both @0.008\%) at pink bud stage followed by spray of oxy-demeton methyl at fruit set stage were found most effective ( $<10 \%$ infestation) in comparison to $55.56 \%$ infestation in control where only water spray was applied. The biopesticides /plant products did not prove effective. Three fourth winter pruning of one year growth was found superior over biopesticides treatments and control.The avoidable loss in the effective treatments was appreciable and the benefit cost ratio was more than 40:1.

Interpretation : The combination based on Neonicotinoid treatments i.e. imidacloprid or thiamethoxam (both @0.008\%) followed by oxy-demeton methyl $(0.025 \%)$ were effective both from bioefficacy and economic points of view in managing (Brachycaudus helichrysi) infestation in nectarines.

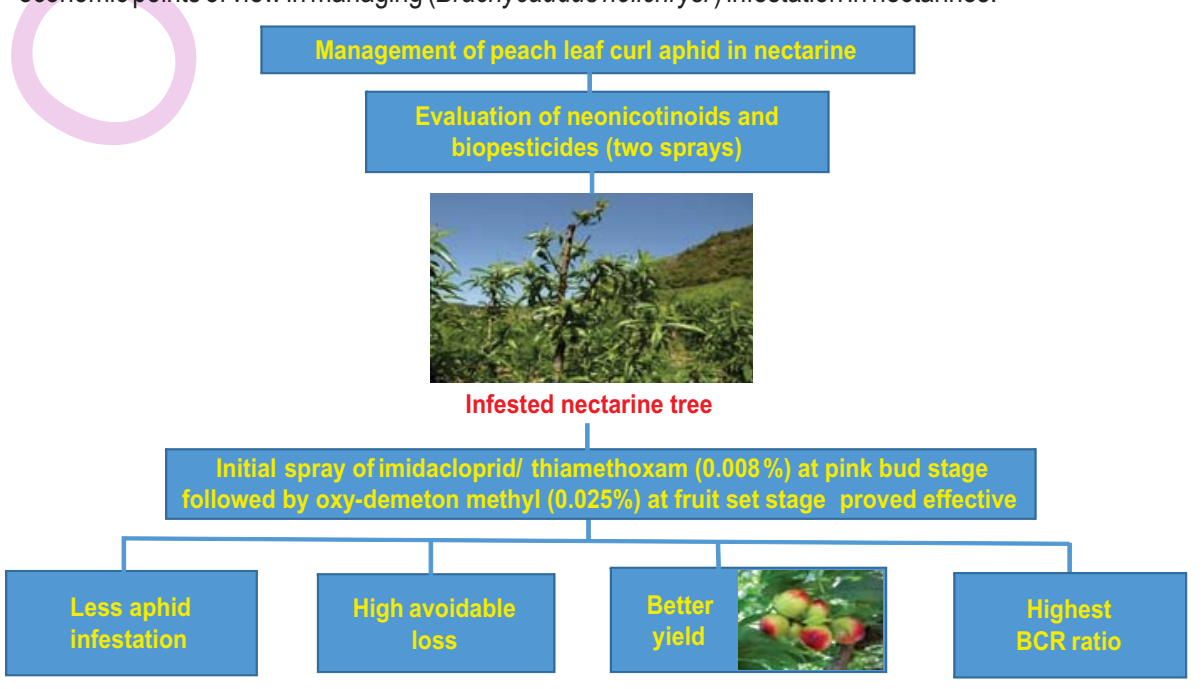




\section{Introduction}

Nectarines (Prunus persica var. nucipersica) are the smooth skinned fruits closely allied to peach and are non pubescent. They have apparently originated from peach by mutation. The outer appearance of the fruit resembles plum but from inside it is like peach. The fruits are smaller, more aromatic than peach and are known for its excellent appearance,juicy content and also is a good source of vitamins and minerals, especially carotene and thiamine. Cultivation of nectarine production is coming up though at a slower pace and the exact figures on area and production are not available.

Peach leaf curl aphid, Brachycaudus helichrysi (Kaltenbach), a pest of regular occurrence, is one of the most destructive pests in peach and nectarine growing areas of the country (Sharma, 2010; Singh et al., 2015) and is a major limiting factor in it's successful cultivation. Besides peach and nectarine, it also infests almonds, apricots, prune and plum. The extent of infestation generally exceeds $50 \%$ if the timely measures are not taken. Most of the management measures used against this pest are insecticide oriented and the insecticides belonging to OP-group namely oxy-demeton methyl, dimethoate and monocrotophos recommended for peach (Gupta, 2013) are being used for this crop also. Since scanty information is available on the management of this pest on nectarine, therefore it was thought imperative to test some neonicotinoids, biopesticides and their combinations against B. helichrysiinfesting nectarine.

\section{Materials and Methods}

The present studies were carried out in a seven year old well managed orchard of nectarine (var. Silver King) in the experimental farm of Department of Fruit Science, Dr. Y. S. Parmar University of Horticulture and Forestry, Nauni situated at an elevation of $1262 \mathrm{~m}$ asl.Three botanicals, namely neem formulation, Econeem 10,000ppm (0.01 and $0.02 \%$ a.i.), neem oil (1.0 and $2.0 \%$ ) and pongamia oil (1.0 and 2.0\%), and two neonicotinoids viz. imidacloprid (Confidor 200SL) and thiamethoxam (Actara 25WG) applied each @0.008 and $0.016 \%$ alongwith the standard recommended insecticide, oxy-demeton methyl (Metasystox 25EC) @0.025\% These chemicals were sprayed twice on the marked trees with the help of a foot sprayer upto run off stage in different combinations. The first spray was given at pink bud stage and repeated at fruit set. Besides, in one of the treatments where no chemical was applied, winter pruning $\left(3 / 4^{\text {th }}\right.$ pruning of oneyear-old shoot done during December) was also evaluated. Whereas in rest of the treatments and control, $1 / 2$ pruning of one year old shoot was done. In control, only water was sprayed. The experiment was laid out in a randomized block design (RBD) and each treatment was replicated thrice having single tree as a replicate. For making proper emulsions of oils, $0.01 \%$ sticker (Indtron-AE) was added in the spray solution. The details of treatments used in the study are given in the tables presented under results.
For evaluating the efficacy of treatments, data on aphid infestation and aphid count were taken at 7, 14 and 21 days after fruit set. For recording infestation, 20 whorls per tree (five each from all the four directions) were randomly observed out of which the number of infested whorls were recorded and thereafter the data were converted into percent infestation. For counting the aphids, destructive sampling was done after 7, 14 and 21 days of fruit set by cutting five infested whorls/tree randomly and keeping them in polythene bags individually which later were brought to the laboratory. The aphids from the individual whorl were dislodged in a glass beaker $(500 \mathrm{ml})$ containing $70 \%$ alcohol with the help of a camel hair brush and number per whorl was counted after decanting off the alcohol and spreading the aphids on a white paper.

The Fruit yield was recorded in each treatment and avoidable loss was worked out as per Pradhan (1964). In order to know the effectiveness of different treatments in monetary terms, the benefit cost ratio was worked out by recording yield in different treatments as well as control taking into account the cost of the test products used for management of the pest, keeping rest of the factors constant. Thereafter, the value of increased yield was worked out at the selling rate of Rs.40 per kg. The ratio between net monetary return and expenditure incurred on test products was calculated in order to find out the benefit cost ratio.

\section{Results and Discussion}

The data on whorl infestation (Table 1) and aphid count (Table 2), when taken after 7 days of second foliar application, revealed that $B$. helichrysi infestation (43.33\%) as well as aphid count (194.33/whorl) was maximum in control,while the minimum $(5.00 \%)$ infestation was recorded in the treatments $T_{19}$ and $T_{20}$ with aphid count of 8.33-9.00 per whorl. Both these treatments were on par with $T_{6}$ and $T_{7}$ with $6.67 \%$ infestation and aphid count of 11.33 and $9.67 /$ whorl, respectively. These treatments were statistically superior to the recommended insecticide treatment $\mathrm{T}_{22}(0.025 \%)$, with infestation of $20 \%$ and aphid count of 63.33 per whorl. However, in the biopesticide/plant product treatments $\left(T_{1}\right.$, $\mathrm{T}_{2}$ and $\mathrm{T}_{3}$ ), the infestation and aphid count were comparatively high $(25.00,36.67$ and $38.33 \%$; 111.67, 143.67 and 135.67 aphids per whorl, respectively), and were statistically inferior to the standard recommended insecticide (oxy-demeton methyl).

After 14 days, the infestation increased slightly but the trend of efficacy of different treatments was almost similar to 7day observation. After 21 days, the increase in infestation in effective treatments (10-13.3\% in $\mathrm{T}_{6}, \mathrm{~T}_{7}, \mathrm{~T}_{19}$ and $\left.\mathrm{T} 20\right)$ was observed against 28.33 and $68.33 \%$ in the standard recommended oxy-demeton methyl and control. The efficacy trend of these test treatments remained almost unchanged as far as aphid count was concerned (23.33-27.67 aphids per whorl in $T_{6}, T_{7}, T_{19}$ and $T_{20}$ ) and were far superior to other treatments/combinations evaluated in the study. Pruning $\left(T_{21}\right.$ with $33.33 \%$ aphid infestation and 156.67 aphids per whorl) proved to be better than control, but was inferior to the 
Table 1 : Bioefficacy of insecticides, biopesticides and their combinations against peach leaf curl aphid, $B$. helichrysi infesting nectarine (based on \% infestation)

\begin{tabular}{|c|c|c|c|c|}
\hline \multirow[t]{2}{*}{ Treatment (Two sprays) } & \multicolumn{3}{|c|}{ Av. whorl infestation (\%) (Days after second spray) } & \multirow[t]{2}{*}{ Mean } \\
\hline & 7 & 14 & 21 & \\
\hline Neem formulation ( $0.01 \%$ a.i.) - neem formulation $\left(0.01 \%\right.$ a.i.) $T_{1}$ & $25.00(29.99)$ & $36.67(37.24)$ & $56.67(48.82)$ & $39.44(38.68)$ \\
\hline Pongamia oil (1\%) - pongamia oil (1\%) $\mathrm{T}_{2}$ & $36.67(37.24)$ & $45.00(42.11)$ & $55.00(47.86)$ & $45.56(42.41)$ \\
\hline Neem oil (1\%) - neem oil (1\%) $\mathrm{T}_{3}$ & $38.33(38.23)$ & $41.67(40.18)$ & $55.00(47.85)$ & $45.00(42.09)$ \\
\hline Neem Formulation (0.01\% a.i. $)$ - oxy-demeton methyl $(0.025 \%) \mathrm{T}_{4}$ & $26.67(31.06)$ & $31.67(34.22)$ & $41.67(40.18)$ & $33.33(35.15)$ \\
\hline Pongamia oil (1\%) - oxy-demeton methyl (0.025\%) $\mathrm{T}_{5}$ & $30.00(33.15)$ & $40.00(39.20)$ & $46.67(47.07)$ & $38.89(38.47)$ \\
\hline Thiamethoxam (0.008\%) - oxy-demeton methyl $(0.025 \%) \mathrm{T}_{6}$ & $6.67(14.75)$ & $10.00(18.43)$ & $13.33(21.33)$ & $10.00(18.17)$ \\
\hline Imidacloprid (0.008\%) - oxy-demeton methyl $(0.025 \%) \mathrm{T}_{7}$ & $6.67(14.75)$ & $8.33(16.59)$ & $11.67(19.88)$ & $8.89(17.07)$ \\
\hline Oxy-demeton methyl $(0.025 \%)$ - thiamethoxam $(0.008 \%) \mathrm{T}_{8}$ & $18.33(25.30)$ & $21.67(27.70)$ & $21.67(27.70)$ & $20.56(26.90)$ \\
\hline Oxy-demeton methyl $(0.025 \%)$ - imidacloprid $(0.008 \%) \mathrm{T}_{9}$ & $16.67(24.04)$ & $18.33(25.30)$ & $25.00(29.99)$ & $20.00(26.44)$ \\
\hline Pongamia oil (1\%) - thiamethoxam $(0.008 \%) \mathrm{T}_{10}$ & $21.67(27.70)$ & $28.33(32.13)$ & $31.67(34.22)$ & $27.22(31.35)$ \\
\hline Pongamia oil (1\%) - imidacloprid $(0.008 \%) \mathrm{T}_{11}$ & $23.33(28.84)$ & $26.67(31.06)$ & $30.00(33.15)$ & $26.67(31.02)$ \\
\hline Neem formulation (0.01\% a.i.) - thiamethoxam $(0.008 \%) \mathrm{T}_{12}$ & $18.33(25.30)$ & $20.00(26.55)$ & $28.33(32.13)$ & $22.22(27.99)$ \\
\hline Neem formulation ( $0.01 \%$ a.i. $)$ - imidacloprid $(0.008 \%) \mathrm{T}_{13}$ & $20.00(26.55)$ & $20.00(26.44)$ & $25.00(29.99)$ & $21.67(27.66)$ \\
\hline Neem formulation ( $0.02 \%$ a.i. $)$ - neem formulation $(0.02 \%$ a.i. $) \mathrm{T}_{14}$ & $23.33(28.84)$ & $33.33(35.24)$ & $46.67(43.07)$ & $34.44(35.72)$ \\
\hline Neem oil $(2 \%)$ - neem oil $(2 \%) T_{15}$ & $30.00(33.15)$ & $36.67(37.24)$ & $46.67(43.07)$ & $37.78(37.82)$ \\
\hline Pongamia oil (2\%) - pongamia oil (2\%) $\mathrm{T}_{16}$ & $30.00(33.15)$ & $36.67(37.24)$ & $45.00(42.11)$ & $37.22(37.50)$ \\
\hline Oxy-demeton methyl $(0.025 \%)$ - imidacloprid $(0.016 \%) \mathrm{T}_{17}$ & $13.33(21.33)$ & $15.00(22.78)$ & $20.00(26.44)$ & $16.11(23.52)$ \\
\hline Oxy-demeton methyl $(0.025 \%)$ - thiamethoxam $(0.016 \%) \mathrm{T}_{18}$ & $13.33(21.33)$ & $18.33(25.30)$ & $18.33(25.30)$ & $16.67(23.97)$ \\
\hline Imidacloprid $(0.016 \%)$ - oxy-demeton methyl $(0.025 \%) \mathrm{T}_{19}$ & $5.00(12.92)$ & $6.67(14.75)$ & $10.00(18.43)$ & $7.22(15.37)$ \\
\hline Thiamethoxam (0.016\%) - oxy-demeton methyl $(0.025 \%) \mathrm{T}_{20}$ & $5.00(12.92)$ & $6.67(14.75)$ & $13.33(21.33)$ & $8.33(16.33)$ \\
\hline Pruning $T_{21}$ & $20.00(26.55)$ & $31.67(34.22)$ & $33.33(35.24)$ & $28.33(32.00)$ \\
\hline Oxy-demeton methyl (0.025\%) - oxy-demeton methyl $(0.025 \%) \mathrm{T}_{22}$ & $20.00(26.55)$ & $21.67(27.70)$ & $28.33(31.03)$ & $23.33(28.79)$ \\
\hline Control (water) $\mathrm{T}_{23}$ & $43.33(41.15)$ & $55.00(47.85)$ & $68.33(55.80)$ & $55.56(48.27)$ \\
\hline Mean & $21.38(26.73)$ & $26.52(30.18)$ & $33.55(34.74)$ & - \\
\hline
\end{tabular}

CD ( $p=0.05)$; Treatment (T): (1.93); Days (D); (0.70) TxD: (3.34); Figures in parentheses are angular transformed values

recommended insecticide treatment- $\mathrm{T}_{22}(28.33 \%$ infestation and 131.33 aphids per whorl).

When the overall means were compared, $T_{6}, T_{7}, T_{19}$ and $T_{20}$ treatments were found on par with one another and superior over rest of the treatments. in $T_{1}$ to $T_{2}$, treatments where biopesticides/plant products were sprayed did not show any promising results as the infestation levels were quite high (39.44 to $45.56 \%$ and aphid count of 152.56 to 185.78), which were inferior over standard recommended insecticide oxy-demeton methyl (23.33\% infestation and 92.67 aphids/whorl) and were only superior to control ( $55.56 \%$ infestation and 254.44 aphids per whorl).

Sharma (2010) reported considerably higher bio efficacy of oxy-demeton methyl at 0.05 and $0.075 \%$ and it was almost as effective as neonicotinoids (imidacloprid and thiamethoxam). In the present study however, relatively higher mean percent whorl infestation (7.22-10.0\%) was obtained in most effective treatments involving neonicotinoids (first spray) and oxy-demeton methyl (second spray). The difference in infestation is attributed to the fact that they used consecutive sprays of same insecticide, whereas in the present study second spray was replaced by oxy-demeton methyl due to less effectiveness than neonicotinoids that might have resulted in faster build up of aphid population resulting in high percent infestation and aphid count. Neonicotinoids have been reported effective against number of aphids. Like green peach aphid, Myzus persicae Sulzer (Kourdoumbalos et al.,2006), woolly apple aphid, Eriosoma lanigerum Kalt. (Singh and Gupta, 2006) and mustard aphid, Lipaphis erysimi Kalt. (Mandal et al., 2012).

Biopesticides were found to be least effective against aphid, though these were superior over control. Palumbo et al. (2001) reported azadirachtin products to be significantly less effective against lettuce aphid. Nasonovia ribisnnigri (Mosley) in comparison to neonicotinoids. 
Table 2 : Bioefficacy of insecticides, biopesticides and their combinations against peach leaf curl aphid, $B$. helichrysi infesting nectarine (based on aphid count)

\begin{tabular}{|c|c|c|c|c|}
\hline \multirow[t]{2}{*}{ Treatment (Two sprays) } & \multicolumn{3}{|c|}{ Av. count of aphid/ leaf whorl (Days after second spray) } & \multirow[t]{2}{*}{ Mean } \\
\hline & 7 & 14 & 21 & \\
\hline Neem formulation ( $0.01 \%$ a.i. $)$ - neem formulation $(0.01 \%$ a.i. $) \mathrm{T}_{1}$ & 111.67 & 151.67 & 194.33 & 152.56 \\
\hline Pongamia oil (1\%) - pongamia oil (1\%) $\mathrm{T}_{2}$ & 143.67 & 182.33 & 231.33 & 185.78 \\
\hline Neem oil (1\%) - neem oil (1\%) $\mathrm{T}_{3}$ & 135.67 & 179.33 & 227.33 & 180.78 \\
\hline Neem Formulation ( $0.01 \%$ a.i. $)$ - oxy-demeton methyl $(0.025 \%) \mathrm{T}_{4}$ & 84.00 & 127.67 & 161.33 & 124.33 \\
\hline Pongamia oil (1\%) - oxy-demeton methyl $(0.025 \%) \mathrm{T}_{5}$ & 88.33 & 156.33 & 187.00 & 143.89 \\
\hline Thiamethoxam $(0.008 \%)$ - oxy-demeton methyl $(0.025 \%) \mathrm{T}_{6}$ & 11.33 & 19.67 & 27.67 & 19.56 \\
\hline Imidacloprid (0.008\%) - oxy-demeton methyl $(0.025 \%) \mathrm{T}_{7}$ & 9.67 & 16.67 & 25.00 & 17.11 \\
\hline Oxy-demeton methyl $(0.025 \%)$ - thiamethoxam $(0.008 \%) \mathrm{T}_{8}$ & 41.67 & 66.00 & 93.67 & 67.11 \\
\hline Oxy-demeton methyl (0.025\%) - imidacloprid (0.008\%) $\mathrm{T}_{9}$ & 39.33 & 68.33 & 91.33 & 66.33 \\
\hline Pongamia oil (1\%) - thiamethoxam $(0.008 \%) \mathrm{T}_{10}$ & 74.00 & 114.33 & 151.00 & 113.11 \\
\hline Pongamia oil (1\%) - imidacloprid (0.008\%) $\mathrm{T}_{11}$ & 69.33 & 96.67 & 139.67 & 101.89 \\
\hline Neem formulation (0.01\% a.i.) - thiamethoxam $(0.008 \%) \mathrm{T}_{12}$ & 56.33 & 79.00 & 106.67 & 80.67 \\
\hline Neem formulation (0.01\% a.i.) - imidacloprid $(0.008 \%) \mathrm{T}_{13}$ & 61.67 & 84.33 & 123.00 & 89.67 \\
\hline Neem formulation ( $0.02 \%$ a.i.) - neem formulation $(0.02 \%$ a.i. $) \mathrm{T}_{14}$ & 90.67 & 129.67 & 169.33 & 129.89 \\
\hline Neem oil $(2 \%)$ - neem oil $(2 \%) T_{15}$ & 101.00 & 138.33 & 180.33 & 139.89 \\
\hline Pongamia oil (2\%) - pongamia oil (2\%) $T_{16}$ & 94.67 & 135.33 & 178.67 & 136.22 \\
\hline Oxy-demeton methyl $(0.025 \%)$ - imidacloprid $(0.016 \%) \mathrm{T}_{17}$ & 21.67 & 39.67 & 57.67 & 39.67 \\
\hline Oxy-demeton methyl (0.025\%) - thiamethoxam $(0.016 \%) \mathrm{T}_{18}$ & 27.00 & 43.67 & 66.33 & 45.67 \\
\hline Imidacloprid $(0.016 \%)$ - oxy-demeton methyl $(0.025 \%) \mathrm{T}_{19}$ & 8.33 & 14.67 & 23.33 & 15.44 \\
\hline Thiamethoxam (0.016\%) - oxy-demeton methyl $(0.025 \%) \mathrm{T}_{20}$ & 9.00 & 15.00 & 24.67 & 16.22 \\
\hline Pruning $T_{21}$ & 81.33 & 122.33 & 156.67 & 120.11 \\
\hline Oxy-demeton methyl (0.025\%) - oxy-demeton methyl $(0.025 \%) \mathrm{T}_{22}$ & 63.33 & 83.33 & 131.33 & 92.67 \\
\hline Control (water) T23 & 194.33 & 265.67 & 303.33 & 254.44 \\
\hline Mean & 70.35 & 101.30 & 132.65 & - \\
\hline
\end{tabular}

$C D(p=0.05) ;$ Treatment: 8.32; Days: 3.00; Treatment x Days: 14.42

The lower efficacy of exclusive biopesticide treatments both with respect of whorl infestation and aphid count can be attributed to their poor contact action against the aphids compared to neonicotinoids and organophosphate insecticide, oxy-demeton methyl which shows translaminar (Jeschke and Ralf, 2012) and systemic action, thereby resulting in high pest mortality compared to plant products. Furthermore, B. helichrysi remains hidden in curled leaves resulting in less exposure to the biopesticides.

Pruning of trees proved superior to a number of treatments (mainly biopesticides) and control. Not much information is available on the effect of pruning on the subsequent population build-up of peach leaf curl aphid. However, Gupta et al. (1988) reported that 1-6\% of total pruned wood contained an egg of the peach leaf curl aphid, $B$. helichrysi. Aphid being a prolific breeder can give birth to as many as $40-66$ stem mothers and fundatrigenae and these stem mothers if have a similar reproductive potential can produce large number of aphids. The workers further opined that elimination of this small proportion of eggs has a substantial impact on reduction of ultimate aphid population. Hence, pruning can be effectively utilized in the integrated management programme of this pest. In the present findings also effectiveness of pruning treatment was probably due to destruction of overwintering eggs.

The avoidable loss (Table-3) was maximum where combination of neonicotinoids with standard synthetic insecticide was followed both at lower $\left(T_{6}, T_{7}\right)$ and higher $\left(T_{19}, T_{20}\right)$ concentrations with $62.77,63.22$ and $64.81,64.71 \%$ avoidable loss. In general, the bio pesticide treatments when used alone recorded the lowest values of avoidable loss ranging between 16.94 and $44.50 \%$, however, their combinations both with oxydemeton methyl and neonicotinoids proved better with 34.71 , 45.97 and $51.55-58.18 \%$ values of avoidable loss for the respective groups of insecticides.

The results of the present study is in confimation with the earlier study of Sharma (2010) who recorded 1.38 times increase in yield in imidacloprid over oxy-demeton methyl $(0.05 \%)$ in 
Table 3 : Avoidable loss and benefit cost ratio of different insecticide treatments, biopesticides and their combinations applied against peach leaf curl aphid $B$. helichrysi infesting nectarine

\begin{tabular}{|c|c|c|c|}
\hline Treatment (Two sprays) & Mean yield (kg per tree) & Avoidable loss & Benefit cost ratio \\
\hline Neem formulation $\left(0.01 \%\right.$ a.i.) - neem formulation $\left(0.01 \%\right.$ a.i.) $\mathrm{T}_{1}$ & 6.13 & 33.64 & * \\
\hline Pongamia oil (1\%) - pongamia oil (1\%) $\mathrm{T}_{2}$ & 4.90 & 16.94 & * \\
\hline Neem oil (1\%) - neem oil (1\%) $\mathrm{T}_{3}$ & 5.03 & 19.14 & * \\
\hline Neem Formulation (0.01\% a.i.) - oxy-demeton methyl $(0.025 \%) \mathrm{T}_{4}$ & 7.53 & 45.97 & 5.53: 1 \\
\hline Pongamia oil (1\%) - oxy-demeton methyl $(0.025 \%) \mathrm{T}_{5}$ & 6.23 & 34.71 & 4.69: 1 \\
\hline Thiamethoxam (0.008\%) - oxy-demeton methyl $(0.025 \%) \mathrm{T}_{6}$ & 10.93 & 62.77 & 41.90: 1 \\
\hline Imidacloprid (0.008\%) - oxy-demeton methyl $(0.025 \%) \mathrm{T}_{7}$ & 11.07 & 63.22 & 51.21: 1 \\
\hline Oxy-demeton methyl $(0.025 \%)$ - thiamethoxam $(0.008 \%) \mathrm{T}_{8}$ & 10.13 & 59.84 & 29.32: 1 \\
\hline Oxy-demeton methyl $(0.025 \%)$ - imidacloprid $(0.008 \%) \mathrm{T}_{9}$ & 11.00 & 63.00 & 45.82: 1 \\
\hline Pongamia oil (1\%) - thiamethoxam $(0.008 \%) \mathrm{T}_{10}$ & 8.40 & 51.55 & 8.41: 1 \\
\hline Pongamia oil (1\%) - imidacloprid $(0.008 \%) \mathrm{T}_{11}$ & 8.53 & 52.30 & 9.94: 1 \\
\hline Neem formulation (0.01\% a.i.) - thiamethoxam $(0.008 \%) T_{12}$ & 9.63 & 57.75 & 8.12: 1 \\
\hline Neem formulation ( $0.01 \%$ a.i.) - imidacloprid $(0.008 \%) T_{13}$ & 9.73 & 58.18 & 9.15: 1 \\
\hline Neem formulation $(0.02 \%$ a.i. $)$ - neem formulation $(0.02 \%$ a.i. $) T_{14}$ & 7.33 & 44.50 & * \\
\hline Neem oil (2\%) - neem oil $(2 \%) T_{15}$ & 6.33 & 35.74 & * \\
\hline Pongamia oil (2\%) - pongamia oil (2\%) $\mathrm{T}_{16}$ & 6.37 & 36.07 & * \\
\hline Oxy-demeton methyl $(0.025 \%)$ - imidacloprid $(0.016 \%) \mathrm{T}_{17}$ & 10.53 & 61.36 & 24.25: 1 \\
\hline Oxy-demeton methyl (0.025\%) - thiamethoxam $(0.016 \%) \mathrm{T}_{18}$ & 10.47 & 61.11 & 16.77: 1 \\
\hline Imidacloprid $(0.016 \%)$ - oxy-demeton methyl $(0.025 \%) \mathrm{T}_{19}$ & 11.57 & 64.81 & 38.88: 1 \\
\hline Thiamethoxam (0.016\%) - oxy-demeton methyl $(0.025 \%) \mathrm{T}_{20}$ & 11.53 & 64.71 & 30.10: 1 \\
\hline Pruning $T_{21}$ & 8.93 & 54.44 & - \\
\hline Oxy-demeton methyl (0.025\%) - oxy-demeton methyl $\mathrm{T}_{22}$ & 9.20 & 55.76 & 41.75: 1 \\
\hline Control (water) $T_{23}$ & 4.07 & - & * \\
\hline$C D(p=0.05)$ & 1.12 & & \\
\hline
\end{tabular}

* Indicate values $<1$; ** indicate oxy-demeton methyl $(0.025 \%)$

peach. Higher number of fruits was also observed on trees treated with imidacloprid (3 sprays @ 0.006 \& 0.008\%) and acetamiprid (0.006 and $0.008 \%)$, which were comparable to oxydemeton methyl $(0.05 \%)$ treatment, which is partially in line with the present findings. Increased fruit yield following insecticide treatments against peach leaf curl aphid have been reported earlier (Misra and Zafar, 2005, Sharma, 2010, Singh et al., 2015) which corroborate the present findings as lower aphid population due to insecticide treatments resulted in less damage which ultimately increased the yield.

The Benefit Cost Ratio (Table-3) was highest (51.21:1) in treatment $T_{7}$ followed by $T_{6}$ where the respective value was 41.90:1. In the recommended insecticide treatment i.e., two sprays of oxy-demeton methyl $(0.025 \%)$, the benefit cost ratio computed was $41.75: 1$. In the recommended insecticide, oxydemeton methyl $(0.025 \%)$, though the infestation percentage was more than double in comparison to neonicotinoid based treatments $\left(T_{6}\right.$ and $\left.T_{7}\right)$, the gap in benefit cost ratio values was not that wide. This is mainly because of less cost of the recommended insecticide (Rs.4.80/tree) in comparison to $T_{6}$ (Rs.6.40 per tree for two sprays) and $\mathrm{T}_{7}$ (Rs.5.36 per tree for two sprays). Similarly, at higher concentration $(0.016 \%)$ of neonicotinoids based treatments $\left(T_{19}\right.$ and $\left.T_{20}\right)$, the infestation was almost similar to lower concentration $(0.008 \%)$, but the gap in benefit cost ratio was more due to more cost of insecticide in $T_{19}$ and $T_{20}$ due to double quantity of neonicotinoids used in these treatments.

In exclusive biopesticide treatments, the BCR values computed were $<1$ indicating that these treatments were not economically viable mainly due to less effectiveness and high cost of the biopesticides. However, when the second spray was substituted by oxy-demeton methyl $\left(T_{4}, T_{5}\right)$ or neonicotinoids $\left(T_{10^{-}}\right.$ $T_{13}$ ), the higher values of benefit-cost ratio were obtained (5.53 and 4.69 for $T_{4}, T_{5}$ and $8.12-9.94$ for $T_{10}-T_{13}$ ).

Throughout the observation period, no phytotoxicity symptoms like leaf tip and surface injury, wilting, vein clearing, epinasty, hyponasty and fruit injury of any kind were seen on any 
of the treated tree. Hence, it can be said that all the test treatments are safe to nectarine trees. Further, it is concluded that initial spray (pink bud stage) of either imidacloprid $(0.008 \%)$ or thiamethoxam $(0.008 \%)$ followed by second spray (fruit set stage)of oxy-demeton methyl $(0.025 \%)$ proved to be effective against $B$. helichrysi infesting nectarine and hence, can be used in the management programme against peach leaf curl aphid.

\section{Acknowledgments}

The authors acknowledge the help received from the Professor and Head of the Department of Entomology and Department of Fruit Science, Dr. Y.S. Parmar University of Horticulture and Forestry, Nauni (Solan) for carrying out the present study.

\section{References}

Gupta, P.R., J. R. Thakur and G. S. Dogra : Management of peach leaf curl aphid, Brachycaudus helichrysi (Kalt.) infesting stone fruits in Himachal Pradesh. J. Tree Sci., 7, 26-30 (1988).

Gupta, P. R.: Pestilence in temperate climate zone and its management. pp.130-51. In: Integrated Pest Management (Eds.: A. K. Dhawan, B. Singh, Manmeet M. Bhullar and R. Arora). Scientific Publishers (India), Jodhpur (2013).

Jeschke, P. and N. Ralf: Nicotinic acetylcholine receptor agonists: Target and selectivity. pp.1126-1225. In: Modern Crop Protection Compounds. Insecticides (W.Kramer, U. Schirmer, P.Jeschke and
M.Witscheleds). Vol. 3, Wiley VCH Verlag GmbH \&Co.KGaA. Germany (2012).

Kourdoumbalos, A.K., J.T. Margaritopoloulos, G. D. Nanos and J.A. Tsitsipis : Alternative aphid control methods for peach production. J. Fruit Ornamental Plant Res., 14, 181-188 (2006).

Mandal, D., P. Bhowmik and M. L. Chatterjee : Evaluation of new and conventional insecticides for the management of mustard aphid, Lipaphiserysimi Kalt. (Homoptera: Aphididae) on rapeseed (Brassica juncea L.). J. Plant Protec. Sci., 4, 37-42 (2012).

Misra, D.N. and M. Zafar : Evaluation of some newer insecticides for the management of leaf curl aphid Brachycaudus helichrysi (Kalt.) in peach orchard under mid hill conditions of Uttaranchal. Environment Ecology, 23, 376-378(2005).

Palumbo, J. C., F. J. Reyes, J. Mullis, C. H. Amaya, A. Ledesma, and L.Carey.: Neonicotinoids and azadirachtin in lettuce: comparison of application methods for control of lettuce aphids. Vegetable Report Series, Arizona, pp. 35-42 (2001).

Pradhan, S.: Assessment of losses caused by insect pests of crops and estimation of insect population. In: Entomology in India (Ed.: N.C. Pant). Entomological Society of India, New Delhi, pp. 17-58 (1964).

Sharma, D.R.: Bioefficacyof insecticides against peach leaf curl aphid, Brachycaudus helichrysi (Kaltenbach) in Punjab. Indian J. Ent., 72, 217-222 (2010).

Singh, B. and D. Gupta : Efficacyof some new insecticides against the woolly apple aphid, Eriosoma lanigerum (Hausmann). Pest Manage. Economic Zoo., 14, 63-66 (2006).

Singh, G., D. Gupta, N.Thakur, R. S. Bhatia and M. Singh : Field efficacy and economics of neonicotinoids and biopesticides against peach leaf curl aphid, Brachycaudus helichrysi (Kalt.). Pest Manage. Horticul. Ecos., 21, 135-144 (2015). 